\title{
O processo de alfabetização e as tecnologias digitais: uma análise sobre o software "Coelho Sabido"
}

\author{
Rita de Cassia de Souza Landin; Giseli de Souza Lucas; Maria Iolanda Monteiro; Pós- \\ Graduação em Educação; Universidade Federal de São Carlos; São Paulo; Brasil; \\ ritalandinead2@gmail.com; giselilucas@hotmail.com; mimonteiro@ufscar.br; \\ Alfabetização no Ensino Fundamental
}

\begin{abstract}
The development of Information and Communication Technologies (BELLONI, 2009) brought more dynamism and interaction in social relations, in the dissemination of news, information and knowledge. Consequently, the relationships between learning and teaching, their space, time and tools and student-teacher-knowledge also changed. Digital technology resources are increasingly present in schools. This study examines the use of educational software "Coelho Sabido" in the literacy process, scoring some positive and negative aspects of a particular activity. Adopt as backrests for literacy and literacy theorists Kleiman (1995), Monteiro (2010) and Soares (2012). At the end it appears that the use of digital technology resources must occur critically and not compulsory.
\end{abstract}

Resumo. O desenvolvimento de Tecnologias da Informação e Comunicação (BELLONI, 2009) trouxe maior dinamicidade e interação nas relações sociais, na difusão de notícias, informações e conhecimentos. Consequentemente, as relações entre o aprender e o ensinar, seus espaços, tempos e ferramentas e a relação aluno-professor-conhecimento também se modificaram. Recursos tecnológicos digitais são cada vez mais presentes nas escolas. Assim, este trabalho analisa o uso do software educativo "Coelho Sabido" no processo de alfabetização, pontuando alguns aspectos positivos $e$ negativos de uma determinada atividade. Adotam-se como respaldos teóricos para alfabetização e letramento Kleiman (1995), Monteiro (2010) e Soares (2012). Ao final infere-se que o uso dos recursos tecnológicos digitais deve ocorrer de forma crítica e não compulsória. 


\section{Introdução}

O desenvolvimento tecnológico, especificamente dos meios de comunicação e informação (BELLONI, 2009), trouxe mudanças significativas para as relações com o conhecimento, à informação e a comunicação. Especificamente, o desenvolvimento do o computador e da internet possibilitou a disseminação de informações de forma quase que instantânea (KENSKI, 2007; 2012). Com a globalização da economia, estes recursos estão sendo utilizados cada vez mais pelos indivíduos e instituições sociais, alterando as formas de comunicação, relações interpessoais, comportamentos, obtenção de informações, conhecimentos e, sobretudo, a maneira de lidar com a aprendizagem (KENSKI, 2007; 2012).

Desde modo, nos últimos anos os governos vêm desenvolvendo políticas públicas de incentivo à informatização das escolas e ao uso de tecnologias digitais no processo de ensino aprendizagem (ALONSO, 2008). Segundo Alonso (2008), programas de distribuição de computadores, notebooks e softwares educativos para as escolas públicas e cursos de capacitação aos professores são algumas medidas que foram adotadas. Entretanto, a autora alerta que a inserção de recursos tecnológicos digitais no processo de ensino e aprendizagem não é sinônima de mais qualidade. Assim, para que o processo de ensino e aprendizagem possa favorecer-se dos recursos tecnológicos digitais, estes precisam ser vistos e analisados criticamente sobre a perspectiva de serem recursos didáticos e metodológicos. Fialho e Mattos (2010) apontam como os recursos tecnológicos digitais mudam também a forma que os aprendizes constroem suas representações sobre o objeto de aprendizagem. Dessa maneira, na próxima seção será apresentada uma análise reflexiva sobre a utilização de um software educativo como ferramenta didática metodológica no processo de alfabetização.

\section{O processo de alfabetização: software "Coelho Sabido" como ferramenta didática e metodológica}

A experiência relatada neste artigo ocorreu no ano de 2009, em uma escola pública do interior do Estado de São Paulo. Este momento foi vivenciado com um grupo de quatro alunos dos anos iniciais do Ensino Fundamental $\left(3^{\circ}, 4^{\circ}\right.$ e $\left.5^{\circ}\right)$, que não estavam alfabetizados e apresentavam dificuldades na compreensão e assimilação das normas de decodificação e codificação para a elaboração da escrita e interpretação de textos; na oralidade os alunos desenvolviam textos de acordo com suas funções e usos sociais, ou seja, eram letrados (KLEIMAN, 1995). Porém, as práticas de leitura e escrita deste grupo ocorriam prioritariamente no ambiente escolar e a marca de oralidade estava muito presente em suas falas. Por distanciarem-se verticalmente dos conhecimentos esperados para sua etapa escolar, eram acompanhados em aulas de apoio com docente específico, com planejamentos didáticos direcionados e materiais didáticos $\mathrm{e}$ metodológicos diversificados, tanto convencionais quanto recursos tecnológicos digitais (BELLONI, 2009).

Um dos recursos tecnológicos digitais utilizados era o software "Coelho Sabido", o qual é um programa de atividades lúdicas e jogos educativos voltados para Educação Infantil e anos iniciais do Ensino Fundamental, apresentando nove títulos específicos para cada etapa escolar. É um produto não gratuito e de código fechado ou 
proprietário ${ }^{1}$. Nesta análise, o software utilizado era o "Coelho Sabido $2^{\circ}$ Ano Nuvem da Alegria (antiga $1^{a}$ Série)", o qual reúne atividades que abordam conteúdos como o reconhecimento de letras, a relação fonema - grafema, leitura de palavras e frases, categorização de elementos, contar, adicionar, subtrair, entre outros.

A atividade em questão constava no reconhecimento de letras, sílabas simples e complexas para a composição de determinadas palavras, as quais eram associadas aos seus respectivos desenhos. O som de cada letra também era reproduzido ao se clicar sobre ela e encaixá-la na palavra; sua leitura, correta ou incorreta, era realizada automaticamente. A atividade apresentava-se para alunos com hipótese de escrita desde o nível pré-silábico até o alfabético (FERREIRO; TEBEROSKY, 1999). Inicialmente, se deveria selecionar uma letra que estava faltando; em outro nível duas; depois as sílabas simples e, assim, sucessivamente. Apenas no último nível havia a possibilidade de construção da palavra toda com sílabas / letras soltas apresentadas de forma aleatória. Em todos os níveis as opções corretas e incorretas apareciam concomitantemente.

Sendo a alfabetização um processo que pode ser compreendido de forma ampla ou restrita (MONTEIRO, 2010), esta atividade apresenta pontos positivos e negativos. Quanto ao caráter restrito da alfabetização, Abud (1987, p.7) expõe que o processo de aquisição do código escrito tem como uma de suas facetas o caráter mecânico de decodificação e codificação dos sinais gráficos. Neste sentido, a alfabetização é "aprendizagem de um verossímil lingüístico, mais ou menos sistematizado na ordem arbitrária do alfabeto e em sua representação fonológica, na ordenação morfológica e léxica das palavras e na articulação sintática das frases e dos textos" (ABUD, 1987, p.7). Assim, a atividade acima descrita torna-se importante no processo de alfabetização no diz respeito à codificação e decodificação dos sinais gráficos que compõe a escrita (MONTEIRO, 2010), associada ao trabalho com a memória visual e auditiva, ao signo e significado, a leitura realizada pelo próprio software como modelo. Ou seja, esta atividade auxilia o aprendiz a desenvolver as habilidades de codificação - decodificação dos sinais gráficos, aprendendo a associação grafema - fonema existente na base do sistema de escrita alfabética da Língua Portuguesa.

Já em seu caráter amplo, a alfabetização se expressa pela capacidade crítica do indivíduo expressar-se com o mundo, integrando-se a sociedade, fazendo uso da escrita e leitura de forma a mudar seu comportamento (MONTEIRO, 2010). Segundo Monteiro (2010) e Soares (2012) apenas a decodificação e codificação dos signos linguísticos não bastam para que o indivíduo aproprie-se das mensagens textuais de forma crítica, compreendendo seus significados e funções sociais. Neste sentido o processo o letramento (KLEIMAN, 1995) é tão importante quanto o processo de alfabetização. Assim, a atividade analisada ao oferecer apenas palavras isoladas e descontextualizadas, partindo de métodos sintéticos (MONTEIRO, 2010) não favorece o processo de alfabetização e letramento. Como é um software de código fechado ou proprietário, não oferece a possibilidade de escolha das palavras a serem escritas ou a inserção de novas, a ordem, e/ou em qual nível começar. O fato do banco de dados da atividade ser restrito

${ }^{1}$ O Software proprietário, particular ou não livre é um software para computadores que é licenciado com direitos exclusivos para o produtor. Conforme o local de comercialização do software este pode ser abrangido por patentes, direitos de autor assim como limitações para a sua exportação e uso em países terceiros. Seu uso, redistribuição ou modificação é proibido, ou requer que você peça permissão, ou é restrito de tal forma que você não possa efetivamente fazê-lo livremente. A expressão foi cunhada em oposição ao conceito de software livre. 
pode conduzir a memorização mecânica das letras, sons e palavras, inibindo o processo de reflexão crítica sobre a construção da escrita e, consequentemente, tendo dificuldades na grafia de palavras desconhecidas (MONTEIRO, 2010). Por fim, as palavras apresentadas seguem a norma padrão da Língua Portuguesa, não considerando as variações linguísticas representadas pelas marcas de oralidade do grupo.

Entretanto, o ensino através de métodos sintéticos, como a silabação, soletração e/ou palavração, não deve ser descartado. Segundo Abud (1987), Monteiro (2010) e Soares (2004), os métodos de alfabetização apresentam características peculiares e direcionam a aprendizagem da leitura e escrita para uma determinada característica da alfabetização. Monteiro e Silva (2010), em uma pesquisa sobre as contribuições das práticas de leitura e escrita de professoras alfabetizadoras bem sucedidas, apontam que muitas dessas docentes utilizavam estratégias didáticas e metodológicas diversificadas, mesclando métodos e considerando as variantes culturais e linguísticas apresentadas pelos alunos. Neste sentido cabe ao professor criar condições pedagógicas para que suas práticas didáticas e metodológicas sejam bem sucedidas (MONTEIRO, 2010), promovendo o alfabetizar letrando.

\section{Considerações finais}

Como Kenski (2012) ressalta, os recursos tecnológicos digitais são, em sua maioria, produzidos longe do contexto educacional, por profissionais não ligados à Educação e têm fins comerciais. Portanto, as compreensões e concepções sobre o processo de aquisição da alfabetização e do letramento, suas características e singularidades, os métodos, suas vantagens e desvantagens e processo de desenvolvimento do aprendiz podem não ser levados em consideração a priori. Assim, reafirmam-se as posições de Alonso (2008) e Kenski (2007; 2012) de que os recursos tecnológicos digitais devem ser utilizados com cautela.

A análise relatada acima reafirma as considerações expostas por Kenski (2012) de que as tecnologias digitais não devem ser vistas como recursos substitutivos ao professor ou uma ameaça ao seu trabalho. Mas devem ser vistas com ferramentas didáticas e metodológicas que exigem dos atores envolvidos no processo de ensino e aprendizagem, especialmente professores, uma nova relação formativa. Embora os recursos tecnológicos digitais tragam novas possibilidades de interação no processo de ensino e aprendizagem, oferecendo ferramentas metodológicas e didáticas mais dinâmicas, devem ser analisados pedagógica e criticamente. Como Alonso (2008) aponta seu uso não deve servir apenas para atender fins políticos e econômicos ou as demandas de desenvolvimento tecnológico social.

Portanto, conhecer as características dos recursos utilizados, assim como a natureza epistemológica que subsidia as suas propostas, também se faz de extrema importância para o desenvolvimento de práticas pedagógicas bem sucedidas. Ou seja, é necessário que os docentes tenham conhecimentos sobre os recursos digitais para além dos usos técnicos cotidianos. Assim, o desenvolvimento e apropriação de conhecimentos pedagógicos (SHULMAN, 2005) específicos sobre estes novos recursos e as diferentes forma de aprendizagem e desenvolvimento do conhecimento (KENSKI, 2012) que imprimem é uma emergência observada nos cursos de formação inicial e continuada de professores. A pesquisa revela a distância ainda existente entre os profissionais que criam softwares e objetos educacionais, as limitações do software no processo de alfabetização e a necessidade de existirem também reflexões em outros contextos de aprendizagem. 


\section{Referências}

Abud, M. J. M. (1987) “O ensino da leitura e da escrita na fase inicial da escolarização". São Paulo: Editora Pedagógica e Universitária.

Alonso, K. M. (2008) Tecnologias da informação e comunicação e formação de professores: sobre rede e escolas. "Educação \& Sociedade", v.29, n.104, p.747-768.

Belloni, M. L. (2009) “O que é mídia-educação”. 3. Ed. Campinas, Autores associados.

Ferreiro, E.; Teberosky, A. (1999) "Psicogênese da língua escrita". Tradução de Diana M. Lichtenstein; Liana Di Marco e Mário Corso. Porto Alegre, Artes Médicas.

Fialho, N. N.; Matos, E. L. M. (2010) A arte de envolver o aluno na aprendizagem de ciências utilizando softwares educacionais. "Educar em Revista", Curitiba, n. esp. 2, p. 121-136. Editora UFPR, 2010. Disponível em: <http://www.scielo.br/scielo.php?script=sci_arttext\&pid=S010440602010000500007\&lng=en\&nrm=iso>. Acessado: em 5 set. 2012.

Kenski, V. M. (2007) "Educação e Tecnologias: o novo ritmo da informação". Campinas, Papirus.

Kenski, V. M. (2012) “Tecnologias e ensino presencial e a distância”. Campinas, Papirus, 2012, $9^{\text {a }}$ edição.

Kleiman, A. B. (Org). (1995) "Os significados do letramento: uma nova perspectiva sobre a prática social da escrita". Campinas, Mercado das Letras.

Monteiro, M. I. ; Silva, L. L. M. (2010) “Contribuições para pensar as práticas de leitura e escrita de professoras das séries iniciais do ensino fundamental". Revista de Educação Publica (UFMT), v. 19, p. 423-442.

Monteiro, M. I. (2010) "Alfabetização e letramento na fase inicial da escolarização". São Carlos, EdUFSCar.

Shulman, L. S. (2005) Conocimiento y enseñanza: fundamentos de la nueva reforma. Granada (Esp). Profesorado. "Revista de curriculum y formación del profesorado", v.9, n.2. Disponível em: http://digibug.ugr.es/bitstream/10481/15244/1/rev92ART1.pdf

Soares, M. (2004) Letramento e alfabetização: as muitas facetas. "Revista Brasileira de Educação", Rio de Janeiro, n. 25, abr. 2004. Disponível em: <http://www.scielo.br/scielo.php?script=sci_arttext\&pid=S1413-

24782004000100002\&lng=pt\&nrm=iso>. Acessado: em 5 set. 2012. 